McGill University Working Paper

\title{
Unveiling Hidden Districts: Assessing the Adoption Patterns of Business Improvement Districts in California
}

\author{
Leah Brooks \\ Department of Economics \\ McGill University
}

May 2006

I am grateful to Tara Syed for research assistance, and to the advice and support of Janet Currie, Jean-Laurent Rosenthal, Naomi Lamoreaux, Paul Ong and Sandy Black at UCLA, to new colleagues Maxim Sinitsyn, Mary MacKinnon, Jenny Hunt, Dee Sutthiphisal, Daniel Parent, and Francisco Alvarez-Cuadrado, the Public Economics group at the CeMent workshop, and the February 2006 Critical Issues Symposium at the DeVoe Moore Center. I am also deeply indebted to the many municipal officials who helped me assemble the dataset and without whose cooperation this project would have been impossible. This work was supported in part by a NBER Non-Profit Dissertation Fellowship, by a grant from the Lincoln Institute for Land Policy, and by funds from McGill University.

(C)2006 by Leah Brooks. 


\section{Unveiling Hidden Districts: Assessing the Adoption Patterns of Business Improvement Districts in California}

A wealth of anecdotal evidence suggests that, in the wake of tax revolts, cities have responded with a proliferation of special assessment districts which directly link taxes and their local public good beneficiaries. Despite this, there is no systematic evidence on the adoption patterns of these districts, likely because they are not surveyed by the U.S. Census of Governments. This paper begins to fill this gap by reporting the results of a survey on the adoption patterns of one class of special assessment districts, Business Improvement Districts (BIDs), in the state of California. A BID is formed when a majority of merchants or property owners in a commercial neighborhood vote in favor of a package of local taxes and expenditures; once passed, assessments are legally binding on all members of the commercial neighborhood. I find that roughly half of all larger cities in California have at least one BID; among the universe of cities in four Southern California counties, that figure falls to about one-fifth. On the demand side, theory and evidence suggest that BIDs should be adopted in heterogeneous cities to supplement local public goods to neighborhood taste. On the supply side, theory argues that BIDs solve the collective action problem arising in the provision of public goods when the number of group members is large. In particular, older commercial neighborhoods have many landowners who may have trouble coordinating the provision of local public goods, in contrast to the single mall developer who can write contracts to internalize externalities. Combining the survey data with demographic, institutional and political data, I find strong support for the supply-side story, and some evidence that the interaction of supply and demand explain BID adoption.

Leah Brooks

Department of Economics

McGill University

Leacock Hall, Rm. 439855 Sherbrooke St., West

Montreal, QC h3a 2 t7

CANADA

leah.brooks@mcgill.ca

http://people.mcgill.ca/leah.brooks/ 
Anecdotal evidence (Chapman, 1998; Fay, 1989; Porter, 1989) suggests that tax and expenditure limits adopted by states in the 1970s have led to a proliferation of special assessment districts. Generally, a special assessment district is a sub-municipal entity that levies taxes on a geographically small district and uses the revenues to fund local improvements in that district. By levying taxes only on districts constructed to directly benefit from those levies, special assessment districts avoid tax revolt strictures. Despite the growing importance of these districts, basic patterns of adoption are unknown. Indeed, because these districts are not surveyed by the Census of Governments, their adoption patterns are a mystery to researchers (see Briffault (1999) for the state of knowledge on special assessment districts). ${ }^{1}$ More broadly, special assessment districts are part of a long research interest in the determinants and consequences of provision of local public goods (Tiebout, 1956; Epple and Romano, 1996; Helsley and Strange, 1999). ${ }^{2}$

This paper begins to fill the gap in knowledge about sub-municipal public goods provision by presenting the results of a survey of California cities describing the adoption patterns of one particular form of special assessment district: the Business Improvement District (BID). In California, a BID is formed when a group of merchants or property owners vote in favor of a package of taxation and local public services. Once a majority of assessment-weighted votes are cast in favor, state law makes the contributions of all neighborhood members mandatory. BIDs provide local public goods such as cleaning, marketing and safety, and are of interest because quantitative analysis shows they have been able to reduce crime in Los Angeles and Philadelphia (Brooks, 2006b; Calanog, 2004; Hoyt, 2005). In addition, anecdotal evidence credits them with a myriad of neighborhood improvements (Houston, Jr., 2003).

Previous work has surveyed existing BIDs (Mitchell, 2001) to determine services and

\footnotetext{
${ }^{1}$ This is in contrast to special districts, which generally provide services such as water or sewage across many municipalities, and which are surveyed by the Census of Governments.

${ }^{2}$ This project is of particular interest because data on other special assessment districts are even more difficult to collect than data on BIDs. Many special assessment districts are neither surveyed by another other level of government or consistently in the same department across cities.
} 
goals, relying on the list of BIDs compiled by the International Downtown Association. While this list likely includes most of the largest BIDs, it is unreliable as a comprehensive survey of BID adoption. To completely capture BID adoption patterns, this paper offers the first comprehensive survey of adoption patterns by city, the jurisdiction that authorizes BIDs in California. I find that roughly half of California cities with a population of at least 25,000 in 1980 have BIDs. Among the sample of all cities in the four largest Southern California counties, almost one-fifth have at least one BID.

What motivates BID adoption at the city level? I propose and test supply and demand side hypotheses. On the demand side, recent work has suggested that more heterogeneous cities should be more likely to either supplement or opt out of government provision (Alesina et al., 1999; Chaudhary, 2005; Poterba, 1997; Temple, 1996). The intuition behind this prediction is that heterogeneous residents may have difficulty agreeing upon a public good of mutual interest.

In contrast, the supply side hypothesis is motivated by the work of Olson (1971), who argues that even groups with common goals face a collective action problem in the provision of public goods. In commercial clusters, local public goods of mutual interest include security, cleanliness and parking. One way to overcome collective action problems in providing these local public goods is an institution that coerces membership. In newer commercial development, such as malls, coercive force is applied by the developer who prices externalities into rental contracts (Gould et al., 2002). In contrast, urban planners have long noted that older commercial areas have no counterpart for the mall developer. Thus, the theory of collective action argues that the BID institution should solve the problem of an inadequate level of public goods only in non-mall commercial areas, which are predominantly in older commercial neighborhoods and cities.

By combining the data from the survey of BIDs with demographic, government and economic data, I test whether these two hypotheses - and the two in conjunction - can 
explain BID adoption. I find that the only persistently significant explanation for BID adoption lies on the supply side: BIDs are consistently adopted by older cities and adoption increases non-linearly in city age. More limited evidence suggests that the interaction of heterogeneity and community age also explains BID adoption, and is consistent with both the supply and demand sides of the theory.

\section{Theoretical Framework}

Consider that BID adoption is a function of both a demand for BID-like services - heterogeneity - and a supply of BID-resolvable difficulties - those problems created by older neighborhoods. On the demand side, I modify the Alesina et al. (1999) model to explain why the heterogeneity of residents should also apply to firms - which BIDs are - and not just residents. The Alesina et al model posits a jurisdiction without mobility, where individuals have preferences over the amount and type of a public good. The jurisdiction chooses its level of public goods first by voting on the size of the public good and then by voting on the type. In equilibrium, as tastes for the public good become more heterogeneous, the jurisdiction provides less of the public goods.

To modify the model, I associate citizens in Alesina's world not just with a city, but also with a neighborhood. In addition, I add two not terribly restrictive assumptions. First, assume that the firms of interest are retail businesses. This conforms very closely with the actual composition of BIDs. Second, assume that firms serve local residents and local public goods such as crime prevention, parking and cleanliness are an important part of the retail shopping experience. Specifically, assume that firms' profits are decreasing in the difference between the municipally provided level of the public good and the locally desired level of the public good. ${ }^{3}$ Formally, this is $\sum_{j}^{J} \min \left(0, g^{*}-g_{j}^{*}\right)$, where $g^{*}$ is the public good provided by

\footnotetext{
${ }^{3}$ In some cities, where small business owners have historically lived over their shops, there could be some confusion between firm and resident. As an empirical matter, this practice is much less frequent in California
} 
the city, and $g_{j}^{*}$ is the level of the public good desired by person $j$ of neighborhood $J$.

Retailers' profit increases as the difference between the municipally chosen level of public good, $g^{*}$, and each neighborhood resident's desired level of public good, $g_{j}^{*}$ shrinks. ${ }^{4}$ From the Alesina et al. (1999) model, we know that the amount of the public good provided by the city, $g^{*}$, declines in consumer heterogeneity. ${ }^{5}$ Because firms' profits are increasing in $g^{*}$, firms are more desirous of supplementing the municipally-provided level of public goods when a city is heterogeneous. In sum, the Alesina et al. (1999) model suggests that more heterogeneous cities are more likely to have supplemental provision of local public goods.

On the supply side, suppose that BIDs resolve a collective action problem in the provision of local public goods in a neighborhood of firms. For example, each firm in a neighborhood would like to provide parking for its customers. Suppose that no firm finds it profitable to provide parking alone, and that parking is not profitably offered by the private market. Because parking for tenants is a local public good for firms, each firm is reluctant to make a commitment to parking without a binding commitment from all other firms. Without a binding commitment, a suboptimal level of parking - perhaps even no parking at all - is provided.

Note that this collective action problem arises only when the number of firms is large and an actor to internalize externalities is lacking. In the urban context, these two elements are closely correlated with the era of development. In older commercial neighborhoods, firms lease from individual property owners. In contrast, in newer commercial neighborhoods firms are typically agglomerated into shopping malls, strip malls or big box centers. In these newer developments, a single developer writes a contract with his many tenants to provide the public goods at issue, in effect internalizing the externalities. Gould et al. (2002) show

\footnotetext{
than in the eastern United States, so this model accords well with the data.

${ }^{4}$ The minimum operator restricts "too much" of the public good from being harmful.

${ }^{5}$ Formally, Alesina et al. (1999) call this heterogeneity the "median distance from the type most preferred by the median voter."
} 
that developers write lease contracts for malls to efficiently allocate space and internalize externalities - such as those generated by anchor stores. In big box developments, where each store provides a wide variety of goods, the number of firms is smaller than in older commercial neighborhoods. Therefore, the BID institution is of use only in older commercial areas; if newer commercial developments are providing sub-optimal levels of public goods, it is not because they have failed to overcome the collective action problem.

In sum, theory suggests that BID adoption should occur in highly heterogeneous cities and in cities with older commercial stock. In particular, BID adoption should be highest in cities where these two factors work in tandem, and I will explore this interaction empirically.

\section{Business Improvement Districts}

Because BID legislation varies by state, this study focuses on one large state - California - in order to look at adoption patterns within an otherwise constant institutional environment. California has had some variant of a BID law on the books since the 1950s, when the state allowed for the taxation of merchants by district to provide parking lots. Over the years, the state has broadened the mandate of these BIDs. In 1989 the state expanded the mandate of permitted services from mostly parking to include marketing and various neighborhood improvements. A major law change in 1995 expanded potential assessees from solely merchants to include commercial property owners and expanded allowable services to security and other larger structural improvements. This new law escapes the stringencies of California's Proposition 13 by calling this tax an assessment, and BID professionals are always careful to refer to the tax as an assessment. Taxation of residents or residential properties is explicitly forbidden in all versions of the law.

In order to establish a BID, commercial property or business owners in a neighborhood 
decide upon a boundary, assessment schedule and budget for the district. ${ }^{6}$ They then attempt to convince their neighbors that they, too, should support the BID. The city administers formal voting, and votes are weighted by assessment. Commercial properties or businesses in BIDs may be assessed in any way commensurate with the benefits that property receives. Usually the assessment of properties is some combination of building square footage, lot square footage, and front footage; for businesses it is frequently a percentage of the city's business license tax. If a majority of assessment-weighted votes are cast in favor of the BID - which is the entire bundle of boundaries, assessments and expenditures for the 1 to 5 year life of the BID - it is established and taxes are mandatory for all merchant owners within the district. The BID then functions as a not-for-profit corporation.

BIDs are quite small. For the city of Los Angeles, I have complete information on each individual BID and offer information on Los Angeles BIDs in 2002 as illustration. In the city of Los Angeles, BIDs are usually much smaller than a square kilometer and account for less than two percent of the city's land area. In 2002, Los Angeles BIDs spent almost 19 million dollars. A third of that expenditure went to security, and the remaining funds went to a mix of marketing, cleaning, special projects and administration. Compared to the hundreds of millions in federal monies spent on the Section 8 housing program or Community Development Block Grants, these numbers may seem small. However, when compared to city spending, BID expenditures are large local investments. The Hollywood Entertainment District BID covers roughly three-quarters of a square kilometer and its $\$ 1.4$ million per square kilometer of security spending slightly exceeds LAPD expenditures of $\$ 1.3$ million per square kilometer in the same area (Los Angeles Police Department, Information Technology Division, 2003; City of Los Angeles, 2003). The Chinatown BID, at 0.3 kilometers square, in addition to spending on security patrols, spends $\$ 280,000$ annually on cleaning and

\footnotetext{
${ }^{6}$ Formally, commercial properties are those zoned commercial by the city. Business are usually found via firms that pay a city's business license tax.
} 
maintenance. In comparison, the city of Los Angeles spends \$55,000 per square kilometer (City of Los Angeles, 2003). ${ }^{7}$ Thus, though BID expenditures may be small in total, they are locally substantial, sometimes outpacing the city's own expenditures.

The very existence of a BID-like entity is strong evidence that neighborhoods have difficulty providing public goods without a coercive mechanism, as theorized by Olson (1971). ${ }^{8}$ Of the 253 cities sampled for this paper, slightly less than one-third had at least one BID in 2000.

\section{Data and Estimation}

The primary data for this research comes from a survey I conducted of 253 cities in California. This sample includes all 114 cities with a population of over 25,000 people in 1980 and the universe of cities in San Diego, Riverside, Orange and Los Angeles counties, which account for an additional 123 cities. $^{9}$ By having data on both large cities and a geographically homogeneous group of small cities, the research can yield conclusions about two types of cities. For each city, I asked how many BIDs of each type (merchant or property) the city had, and if there were any BIDs, what year the earliest BID was adopted. I first searched for each city's BIDs online. If that search did not produce any evidence of a BID, I searched the city's own webpage to find information about BIDs. Always as a supplement, and if neither of these methods revealed any information, as it frequently did not, I called or emailed the city to ask an economic development official about BIDs in that city, ${ }^{10}$ and took that official's

\footnotetext{
${ }^{7}$ BID information for the city of Los Angeles comes from city council files.

${ }^{8}$ Prior to the widespread adoption of BIDs, cities used the coercive mechanism of eminent domain to resolve the collective action problem by grouping parcels and re-selling larger lots to developers. Amid charges of racism and developer cronyism, this solution to the collective action problem has fallen from favor.

${ }^{9}$ I surveyed the county of Los Angeles in 2004; the remaining cities were surveyed in late 2005 and early 2006.

${ }^{10}$ In general, I enquired whether a city had any BIDs, so the data are most complete for BIDs as of this decade. In very few instances did a city say that it had a BID in the past and did not have one now. I also did not count as BIDs the very few cases where city officials described a mechanism for hotel marketing that
} 
word as the final say. ${ }^{11}$

Through repeated calling, this survey has a 97 percent response rate, so it reliably covers the universe of cities surveyed. ${ }^{12}$ The third row of Table 2 shows mean BID adoption by group: among Southern California cities, roughly one-fifth have any BIDs; for larger cities the share is roughly half. In both groups, as shown in the fourth row of Table 2, BID-adopting cities are more populous than the non-adopting cities, though the bias is less strong in the sample of larger cities.

To give a sense of BID prevalence, Table 1 lists the twenty largest cities in California, and shows that only seven do not have any BIDs. All of the five largest cities - Los Angeles, San Diego, San Jose, San Francisco and Long Beach - have BIDs, as do eight of the ten largest. The oldest BID among this sample started in 1966 in Modesto.

In order to evaluate whether supply- or demand-side factors lead to BID adoption, I combine the survey data with data from a variety of sources. Because the survey data include year of BID adoption, I am able to construct a panel of observations at the city-year level. From the 1980, 1990 and 2000 decennial censuses, I add data on population, income, race, and household and housing characteristics. From the 1977, 1987, and 1997 economic censuses I use data on the value of retail sales; from the 1982, 1987, and 1997 government censuses I use city expenditure per capita. ${ }^{13}$ Data on crime by city comes from the FBI's Uniform Crime Reports from 1980, 1990 and 2000; information on municipal institutions, including year of incorporation, comes from the 1987 Census of Governments.

To measure the demand side variable of interest, heterogeneity, I calculate the index of functions under the BID statute.

${ }^{11}$ Note that because BIDs are economic-development oriented, they are relatively easy to find within the city bureaucracy. Other special districts, such as those that collect for local parks or lighting can be nearly impossible to find in any systematic fashion. For example, in the city of San Diego, the Parks Department is in charge of administrating special assessment districts.

${ }^{12}$ This sample does not include the eight cities (from the four Southern California counties, San Jacinto; from the larger cities sample, Martinez, Ontario, Upland, Milpitas, Santa Clara, Sunnyvale and West Sacramento) I was forced to drop that did not respond to repeated enquires.

${ }^{13}$ See the appendix for a complete list of control variables. 
fragmentation or Herfindahl index, $H$ for correlates of demand for public goods: income, education and race. ${ }^{14}$ This index is calculated as $H=\sum_{i=1}^{n} s_{i}^{2}$, where $n$ is the number of groups (e.g., income categories) and $s_{i}$ is the share of each group in the population. For example, if a city is $1 / 3$ low income, $1 / 3$ medium income and $1 / 3$ high income, the city has $H=1 / 3$; if all citizens are high income, $H=1$. Thus, the index goes from zero to one, where a heterogeneous city with population split equally between a large number of groups has an index approaching zero, and a homogeneous city with all members in one group has an index of one. ${ }^{15}$ Prior research (Alesina et al., 2004; Vigdor, 2004) has found racial heterogeneity to be more predictive of lowered levels of public goods than heterogeneity of income or education. However, because the public goods at issue here are those which are important to firms, and possibly less redistributional in nature, it is plausible that racial heterogeneity should be less salient in this instance than heterogeneity of income or education.

To measure the supply side of BID adoption, I use two variables which capture the quantity of older commercial infrastructure, and denote their vector as age $e_{i, t}$. First, the Census measures the era of residential construction by neighborhood, and I use this to construct the share of residential buildings constructed after 1940 by city. Unfortunately, this measure does not contain much variance. For the sample of larger cities, the 10th to 90th percentile range is 0.78 to 0.99 , and for the Southern California sample, it is 0.81 to 0.995 with a mean of 0.95 . In additional, while the age of commercial structures should be correlated with the age of residential structures, the relationship may be weak.

The ideal measure of a city's age of commercial infrastructure would be the era when the size of parcels and the size and shape of the street grid were formed. Following the work of Jacobs (1961), these variables determine how firms and properties relate economically to one another, and how they jointly demand local public goods. Because the census data capture

\footnotetext{
${ }^{14}$ This index is identical to the Herfindahl index for measuring concentration within an industry.

${ }^{15}$ In related research, I focus exclusively on comparing spatial and non-spatial measures of heterogeneity to see which best explains BID adoption (Brooks, 2006a).
} 
only the age of currently existing construction, they obscure the initial era of development. However, cities choose to incorporate, in part to have control over exactly these elements of land use regulation, and the year of incorporation is observable.

Thus, the second and preferred measure of the age of commercial infrastructure, likely more closely correlated with the collective action costs commercial neighborhoods face, is a city's year of incorporation. Indeed, even while buildings are replaced, infrastructure, in the form of the street grid and property parcels, is much more costly to replace. To test whether a city's year of incorporation is correlated in any meaningful way to the initial era of development, I use information from the Los Angeles County Assessor's Office on the age of all structures in the 87 cities in Los Angeles county. For each city, I know the age of the primary building on each individual property. If the year of incorporation is a good measure of the era of initial commercial development, the year of incorporation should be correlated with lower percentiles in the distribution of building age. This is indeed the case: among the 87 cities in Los Angeles county, the correlation between the year of incorporation and fifth percentile of the building age distribution is 0.59 ; the correlation with the tenth percentile is 0.55. Among the thirty cities in Los Angeles County over 50,000 people in 1980, the correlations are even stronger -0.68 and 0.70 , respectively. Thus, particularly for larger cities, year of incorporation tracks closely the city's initial era of development.

Combining these measures, I determine the impact of supply and demand factors on BID adoption at the city level by estimating

$$
\begin{gathered}
\operatorname{Pr}\left(\mathrm{BID}_{i, t}=1 \mid \text { het }_{i, t}, \text { age }_{i}, \text { controls }_{i, t}, \text { year }_{t}\right) \\
=\Phi\left(\alpha_{0}+\alpha_{1} \text { het }_{i, t}+\alpha_{2} \text { age }_{i}+\alpha_{3} \operatorname{controls}_{i, t}+\alpha_{4, t} \text { year }_{t}\right) .
\end{gathered}
$$

Observations are at the city-year level and the binary choice of whether or not a city $i$ has any BIDs at time $t, \mathrm{BID}_{i, t}$, is determined by a measure of heterogeneity, het ${ }_{i, t}$, a vector measure 
of city age, age ${ }_{i}$, a vector of demographic, institutional and business controls, controls ${ }_{i, t}$, and

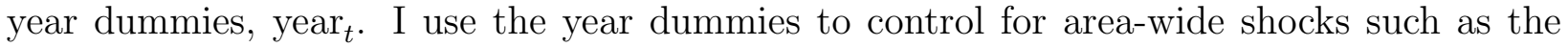
decline of the aerospace industry, which could affect the regional provision of public goods. Heterogeneity is decreasing from 0 to 1 , so if it is associated with BID adoption, $\alpha_{1}$ will be negative. Age is measured by the city's year of incorporation and the share of residential buildings constructed after 1940; if older infrastructure is associated with BID adoption, $\alpha_{2}$ should be less than zero.

Note that the estimation does not include city fixed effects. Across the heterogeneity variables, the variance between cities is usually roughly double the variance within cities. Also, conceptually, restricting the model with city-level fixed effects would require all identification of BID adoption to come from changes within a city, whereas the theory concentrates on a city's long-term level of heterogeneity. ${ }^{16}$ Using fixed effects would also preclude including a city's year of incorporation, which does not vary over time.

In order to estimate the joint impact of the supply- and demand-side factors, I use two interactions. An interaction is preferred to summing the two linear effects, because it is theoretically quite plausible that BIDs arise only when both the supply- and demand-side factors are present together. In such an event, the individual coefficients would not follow a linear function, and their sum would be misleading. The first interaction is thus between heterogeneity and the year of incorporation: $H * \operatorname{incorp}_{i, t}$. If heterogeneity and city age are only explain BID adoption together, then the coefficient on the interaction should be negative and significant, while the main effects may be zero.

The second interaction to estimate the joint impact of heterogeneity and city age is an interaction of dummy variables, which I use to pinpoint where I expect the impact on BID adoption to be strongest. For the measure of heterogeneity, I create two dummy variables:

\footnotetext{
${ }^{16}$ I do cluster standard errors at the city level in order to correct for the repeated observations of multiple cities which would otherwise overstate the true degrees of freedom in the regression.
} 
one if the measure is in the top half, $H_{h i g h}$, of the distribution and one if the measure is in the bottom half, $H_{\text {low }}$. Similarly, I construct two dummies for the age distribution, incorp new

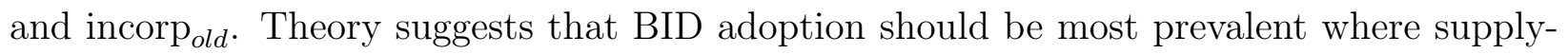
and demand-side factors interact, or when a city is old and heterogeneity is high. This pair is one of the four combinations of dummy interactions: $H$ low and new incorporation year, $H$ high and new incorporation year, $H$ low and old incorporation year, and $H$ high and old incorporation year. Thus, if BID adoption is compelled by a supply- and demand-side interaction, the coefficient on the final dummy interaction should be positive and significant.

\section{Results}

Summary statistics in Panel A of Table 2 show that BID cities are, on average, more populous and have higher per capita city government expenditures than non-BID cities. Among the Southern California cities, the mean population of cities with BIDs is roughly five times the mean population of cities without BIDs. Among the larger cities, cities with BIDs, at a mean population of 220,000, are roughly twice the size of the non-BID cities. No clear pattern or differences emerge in median family income between BID- and non-BID cities.

The remainder of the table compares BID and non-BID cities on the supply- and demandside measures. For both samples, Panel B shows that for poverty, family income and education, cities with BIDs are significantly more heterogeneous than cities without BIDs. For heterogeneity of household type, age and race, no clear pattern emerges in either sample. Panel C shows that cities with BIDs are substantially older than cities without BIDs - a mean incorporation year of 1907 versus 1938 for the Southern California sample, and 1886 vs. 1916 for the larger cities sample - and have slightly less post-1940 residential construction.

Turning to the estimation, Table 3 shows the results of estimating Equation 1 for all larger cities in California, focusing on the heterogeneity of poverty; a later table will present results 
for all types of heterogeneity. Each column in each panel presents the results from a separate regression. The first set of three regressions in Panel A considers the impact of heterogeneity $(H)$ of poverty and share of residential construction post-1940 (column 1); $H$ and year of incorporation (column 2); and the interaction of $H$ and the year of incorporation (column 3). All coefficients are marginal effects at the mean of the regressors from probit estimations and control for the "basic" set of covariates: population and its square, racial composition, household composition, income and characteristics of the city's business environment.

Columns one and two show that heterogeneity marginally significantly explains BID adoption, and that the year of incorporation has more explanatory power for BID adoption than the share of post-1940 residential stock. Results not presented show that the pattern of the superior explanatory power of the year of incorporation persists even controlling for the share of post-1940 residential stock. For this reason, the bulk of the analysis focuses on the year of incorporation. Column 3 shows that adding the interaction between the measure of heterogeneity and the year of incorporation likely leads to multi-collinearity problems because the coefficient on heterogeneity increases twenty times.

Adding additional controls, institutional features in columns four through six, and crime and clearance rates in columns seven to nine, does not change the qualitative picture. Heterogeneity of poverty remains marginally significant, but the year of incorporation remains persistently statistically significant in explaining BID adoption. All specifications with the interaction are plagued by multicollinearity. The coefficient on year of incorporation suggests that increasing a city's age by thirty years - the mean difference between BID and non-BID cities in the sample of larger cities - increases the likelihood of BID adoption by roughly two percentage points. The coefficient on heterogeneity is very large; a coefficient on an index from zero to one, explaining a dichotomous outcome, should be between zero and one, and this is not the case here. This is likely attributable to the fact that the measure of heterogeneity does not span the entire zero-one range. The 10th-90th percentile range 
for heterogeneity of poverty in the larger cities sample is 0.32 (Los Angeles) to 0.75 (Beverly Hills is 0.72) and the equivalent range for the southern California sample is only slightly wider, going from 0.30 to 0.82 . Thus, considering only plausible changes in the heterogeneity variable, the coefficient is more realistic.

The specification using the interaction of dummy variables, presented in Panel B of Table 3 looks more closely at the interaction obscured by problems of multi-collinearity in the top half of the table. This specification includes three dummy variable interactions for whether heterogeneity is high and the city is old, heterogeneity is low and the city is old, and heterogeneity is high and the city is new. All coefficients are in reference to the omitted group - new, homogeneous cities - the theoretically least likely to form a BID. Theory suggests that the high heterogeneity and old year of incorporation interaction should best explain BID adoption at the city level, and this prediction is borne out in this table. Regardless of controls, the high heterogeneity-low incorporation year combination has the largest coefficient, and the only statistically significant one. Being in the high heterogeneity low incorporation year group raises the likelihood of adopting a BID by more than a third.

Do the dynamics that explain BID adoption for larger cities hold for the sample of all cities in four Southern California counties? Table 4 presents results for the same estimations as Table 3 with this different sample. As before, Panel A shows that, regardless of controls, age of incorporation explains BID adoption better than the share of post-1940 era residential construction. The coefficient on year of incorporation is roughly the same size as the coefficient from the previous table. As before, the specification with the interaction creates large changes in the coefficients of the main effects, and thus I hesitate to draw conclusions from that specification. The bottom panel of Table 4 repeats the dummy variable specification from the previous table. In the most complete specification, I fail to find any evidence that the high heterogeneity old incorporation year combination explains BID adoption better than either of the other combinations. 
To test whether the interaction is significant across different measures of heterogeneity, Table 5 presents results for heterogeneity of education, family income, age, household type, and race. ${ }^{17}$ The first column in each panel of the table repeats the results for heterogeneity of poverty from the previous tables. In the top panel, which presents results for all larger cities in California, the pattern of the preferred high heterogeneity-low incorporation year dummy being the best explanation for BID adoption holds for two of the six specifications; those using the heterogeneity of poverty and age. For another two specifications, the low heterogeneity low incorporation year combination explains BID adoption equally as well as the preferred combination. For heterogeneity of education, the low heterogeneity low incorporation year combination best explains BID adoption. In the specification using heterogeneity of race, none of the coefficients is significant. Among Southern California cities, described in the bottom panel of Table 5, no clear pattern among any of the three groups emerges.

To push the results on age of incorporation, I divide cities into four rough quartiles by year of incorporation and present results replacing the continuous variable with these dummies. If age matters, we should expect that the oldest cities should be most likely to adopt BIDs, and that the propensity to adopt a BID should decline in age. The first column of Table 6 shows that this prediction holds true examining the raw percentages. The remaining columns of the table present marginal probabilities from a probit model controlling for three measures of heterogeneity - that of poverty, education and family income - and the full set of controls from the previous tables. ${ }^{18}$ The result continues to hold even when a variety of controls are added: if a city was established before 1890 it has a somewhat larger than 50 percent greater likelihood of adopting a BID relative to cities established after 1950 (the omitted group). Cities established between 1890 and 1910 are roughly 40 percent more likely to adopt BIDs than the newest cities, and cities established between 1910 and 1950 are between 35 and 40

\footnotetext{
${ }^{17}$ Results from the continuous specification find BID adoption declines in city age and is generally increases statistically insignificantly in heterogeneity.

${ }^{18}$ Results using the other heterogeneity variables, not pictured, are very similar.
} 
percent more likely.

\section{Conclusions}

The survey evidence presented here, the first to systematically document adoption patterns of special assessment districts by city, shows that BIDs are widespread among larger cities in California, and prevalent but not extremely frequent among all cities in the four largest Southern California counties. In broad terms, these results tell us that BID adoption has become an increasingly frequent mechanism for the provision of local public goods, and thus that the consequences of BID adoption - the quality of public goods they provide, and their impact on the distribution of public goods - are worthy of further study. The results also suggest that the entire class of special assessment districts has an importance not yet documented in the literature.

Contrasting supply- and demand-side explanations for BID adoption at the city level, I find that heterogeneity is, at best, an infrequent explanation for BID adoption. However, a city's year of incorporation is persistently significantly associated with BID adoption, consistent with BIDs resolving a collective action problem endemic to older commercial neighborhoods. This result speaks clearly to a role for public policy in resolving issues of urban decline. 


\section{References}

Alesina, Alberto, Baquir, Reza, and Easterly, William, 1999. "Public Goods and Ethnic Divisions." Quarterly Journal of Economics pages 1243-1284.

Alesina, Alberto, Baquir, Reza, and Hoxby, Carolyn, 2004. "Political Jurisdictions in Heterogeneous Communities." Journal of Political Economy 112(2): 348-396.

Briffault, Richard, 1999. "Government for Our Time? Business Improvement Districts and Urban Governance." Columbia Law Review 99(2): 365-477.

Brooks, Leah, 2006a. "Does Spatial Variation in Heterogeneity Matter? Assessing the Adoption Patterns of Business Improvement Districts." McGill University Working Paper.

Brooks, Leah, 2006b. "Volunteering to Be Taxed: Business Improvement Districts and the Extra-Governmental Provision of Public Safety." McGill University working paper.

Calanog, Victor Franco M., 2004. "Business Improvement Districts: Crime Deterrence or Displacement?" Unpublished manuscript.

Chapman, Jeffrey, 1998. "Proposition 13: Some Unintended Consequences." Proceedings of the Tenth Annual Envisioning California Conference Sept.

Chaudhary, Latika, 2005. "Social Divisions and Public Goods Provision: Evidence from Colonial India." Unpublished manuscript.

Epple, Dennis and Romano, Richard, 1996. "Public Provision of Private Goods." Journal of Political Economy 104: 57-84.

Fay, Jeanie, 1989. "How California's Cities Are Using Mello-Roos." In "Capital Projects: New Strategies for Planning, Management and Finance," International City Management Association.

Gould, Eric D., Pashigian, Peter B., and Prendergast, Canice, 2002. "Contracts, Externalities and Incentives in Shopping Malls." CEPR Discussion Paper No. 3598.

Helsley, Robert W. and Strange, William C., 1999. "Gated Communities and the Economic Geography of Crime." Journal of Urban Economics 46: 80-105.

Houston, Jr., Lawrence O., 2003. Business Improvement Districts. Urban Land Institute in cooperation with the International Downtown Association, second edn.

Hoyt, Lorlene, 2005. "Do Business Improvement District Organizations Make a Difference?" Journal of Planning Education and Research 25: 185-199.

Jacobs, Jane, 1961. The Death and Life of Great American Cities. New York: Random House. 
Mitchell, Jerry, 2001. "Business Improvement Districts and the 'New' Revitalization of Downtown." Economic Development Quarterly 15(2): 115-123.

Olson, Mancur, 1971. The Logic of Collective Action: Goods and the Theory of Groups. Harvard University Press.

Porter, Douglas, 1989. "Financing Infrastructure with Special Districts." In "Capital Projects: New Strategies for Planning, Management and Finance," International City Management Association.

Poterba, James M., 1997. "Demographic Structure and the Political Economy of Public Education." Journal of Policy Analysis and Management 16(1): 48-66.

Temple, Judy A., 1996. "Community Composition and Voter Support for Tax Limitations: Evidence from Home Rule Elections." Southern Economic Journal 62(4): 1002-1016.

Tiebout, Charles M., 1956. "A Pure Theory of Local Expenditures." Journal of Political Economy 64(5): 416-424.

Vigdor, Jacob L., 2004. "Community Composition and Collective Action: Analyzing Initial Mail Response to the 2000 Census." Review of Economics and Statistics 86: 303-312. 
Table 1: BIDs in California's Twenty Largest Cities

\begin{tabular}{lccc}
\hline \hline City & 2000 Population & Any BIDs? & Year of Incorporation \\
\hline Los Angeles & $3,694,834$ & Yes & 1925 \\
San Diego & $1,223,341$ & Yes & 1850 \\
San Jose & 893,889 & Yes & 1850 \\
San Francisco & 776,733 & Yes & 1850 \\
Long Beach & 461,381 & Yes & 1897 \\
Fresno & 427,224 & No & 1885 \\
Sacramento & 407,075 & Yes & 1849 \\
Oakland & 399,477 & Yes & 1859 \\
Santa Ana & 337,512 & Yes & 1869 \\
Anaheim & 327,357 & No & 1857 \\
Riverside & 255,093 & Yes & 1883 \\
Bakersfield & 247,385 & No & 1898 \\
Stockton & 242,714 & Yes & 1850 \\
Fremont & 203,413 & No & 1956 \\
Glendale & 195,047 & No & 1906 \\
Huntington & & & \\
Beach & 189,940 & Yes & 1909 \\
Modesto & 189,460 & Yes & 1884 \\
San Bernardino & 185,388 & No & 1905 \\
Chula Vista & 173,860 & Yes & 1911 \\
Oxnard & 170,595 & No & 1903 \\
\hline \hline & & & \\
\hline
\end{tabular}

Notes: This table reports BID adoption patterns in California's 20 largest cities, and shows that the overwhelming majority have at least one BID.

Source: Self-collected survey data on BID adoption, population from 2000 Census Summary Tape File 3A, and year of incorporation from 1987 Census of Governments. 
Table 2: Comparing BID and Non-BID Cities

\begin{tabular}{|c|c|c|c|c|c|c|}
\hline \multirow[b]{2}{*}{ A. General Characteristics } & \multicolumn{2}{|c|}{$\begin{array}{c}\text { All Southern California } \\
\text { Cities }\end{array}$} & \multicolumn{4}{|c|}{$\begin{array}{c}\text { All Larger California } \\
\text { Cities }\end{array}$} \\
\hline & w/o BIDs & with BIDs & & w/o BIDs & with BIDs & \\
\hline Unique Cities in 2000 & 132 & 27 & & 58 & 56 & \\
\hline City-Year Observations & 408 & 57 & & 220 & 122 & \\
\hline Share of Total in 2000 & 0.83 & 0.17 & & 0.51 & 0.49 & \\
\hline Share with any property-based BIDs & & 0.22 & & & 0.27 & \\
\hline Population & $\begin{array}{c}54,318 \\
(164,540)\end{array}$ & $\begin{array}{c}292,962 \\
(680,962)\end{array}$ & * & $\begin{array}{l}102,836 \\
(226,448)\end{array}$ & $\begin{array}{c}220,698 \\
(489,910)\end{array}$ & * \\
\hline Median family income, $\$ 1,000$ s & $\begin{array}{c}56.4 \\
(42.8)\end{array}$ & $\begin{array}{c}60.5 \\
(33.3)\end{array}$ & & $\begin{array}{c}46.4 \\
(26.2)\end{array}$ & $\begin{array}{c}58.0 \\
(28.4)\end{array}$ & * \\
\hline Per capita city expenditures 2000 & $\begin{array}{c}581.13 \\
(441.92)\end{array}$ & $\begin{array}{c}921.50 \\
(502.37)\end{array}$ & * & $\begin{array}{c}602.33 \\
(403.73)\end{array}$ & $\begin{array}{l}913.60 \\
(585.54)\end{array}$ & * \\
\hline N for city expenditures (city-year obs.) & 158 & 49 & & 220 & 122 & \\
\hline B. Demand-Side Measures: Herfindahl Index & & & & & & \\
\hline Poverty & $\begin{array}{c}0.57 \\
(0.20)\end{array}$ & $\begin{array}{c}0.50 \\
(0.15)\end{array}$ & * & $\begin{array}{c}0.56 \\
(0.16)\end{array}$ & $\begin{array}{c}0.52 \\
(0.15)\end{array}$ & * \\
\hline Family Income & $\begin{array}{c}0.10 \\
(0.05)\end{array}$ & $\begin{array}{c}0.08 \\
(0.02)\end{array}$ & * & $\begin{array}{c}0.09 \\
(0.03)\end{array}$ & $\begin{array}{c}0.08 \\
(0.02)\end{array}$ & * \\
\hline Education & $\begin{array}{c}0.21 \\
(0.08)\end{array}$ & $\begin{array}{c}0.17 \\
(0.05)\end{array}$ & * & $\begin{array}{c}0.21 \\
(0.07)\end{array}$ & $\begin{array}{c}0.17 \\
(0.05)\end{array}$ & * \\
\hline Household Type & $\begin{array}{c}0.32 \\
(0.04)\end{array}$ & $\begin{array}{c}0.33 \\
(0.08)\end{array}$ & & $\begin{array}{c}0.30 \\
(0.03)\end{array}$ & $\begin{array}{c}0.32 \\
(0.05)\end{array}$ & * \\
\hline Age & $\begin{array}{c}0.33 \\
(0.03)\end{array}$ & $\begin{array}{c}0.33 \\
(0.04)\end{array}$ & & $\begin{array}{c}0.32 \\
(0.02)\end{array}$ & $\begin{array}{c}0.32 \\
(0.02)\end{array}$ & \\
\hline Race & $\begin{array}{c}0.62 \\
(0.19)\end{array}$ & $\begin{array}{c}0.54 \\
(0.18)\end{array}$ & * & $\begin{array}{c}0.57 \\
(0.19)\end{array}$ & $\begin{array}{c}0.56 \\
(0.18)\end{array}$ & \\
\hline $\mathrm{N}$ & 399 & 57 & & 220 & 122 & \\
\hline C. Supply-Side Measures: Age of Insfrastru & & & & & & \\
\hline Year of Incorporation & $\begin{array}{c}1938 \\
(29)\end{array}$ & $\begin{array}{c}1907 \\
(31)\end{array}$ & * & $\begin{array}{c}1916 \\
(33)\end{array}$ & $\begin{array}{c}1886 \\
(24)\end{array}$ & ^ \\
\hline $\mathrm{N}$ & 378 & 57 & & 220 & 122 & \\
\hline Share of Residential Construction post-1940 & $\begin{array}{c}0.93 \\
(0.09)\end{array}$ & $\begin{array}{c}0.89 \\
(0.09)\end{array}$ & * & $\begin{array}{c}0.92 \\
(0.09)\end{array}$ & $\begin{array}{c}0.87 \\
(0.11)\end{array}$ & * \\
\hline $\mathrm{N}$ & 399 & 57 & & 220 & 122 & \\
\hline
\end{tabular}

* Significant difference at the $0.05 \%$ level.

Notes: This table compares cities with and without Business Improvement Districts (BIDs). Figures reported are means, with standard deviations below means. Herfindahl indices are calculated from the categories given by the census. Panels B and C report values for the largest balanced panel.

Source: Self-collected survey data on BID adoption; see appendix for complete source list. 
Table 3: The Impact of Heterogeneity of Poverty and Age on BID Adoption in Larger Cities

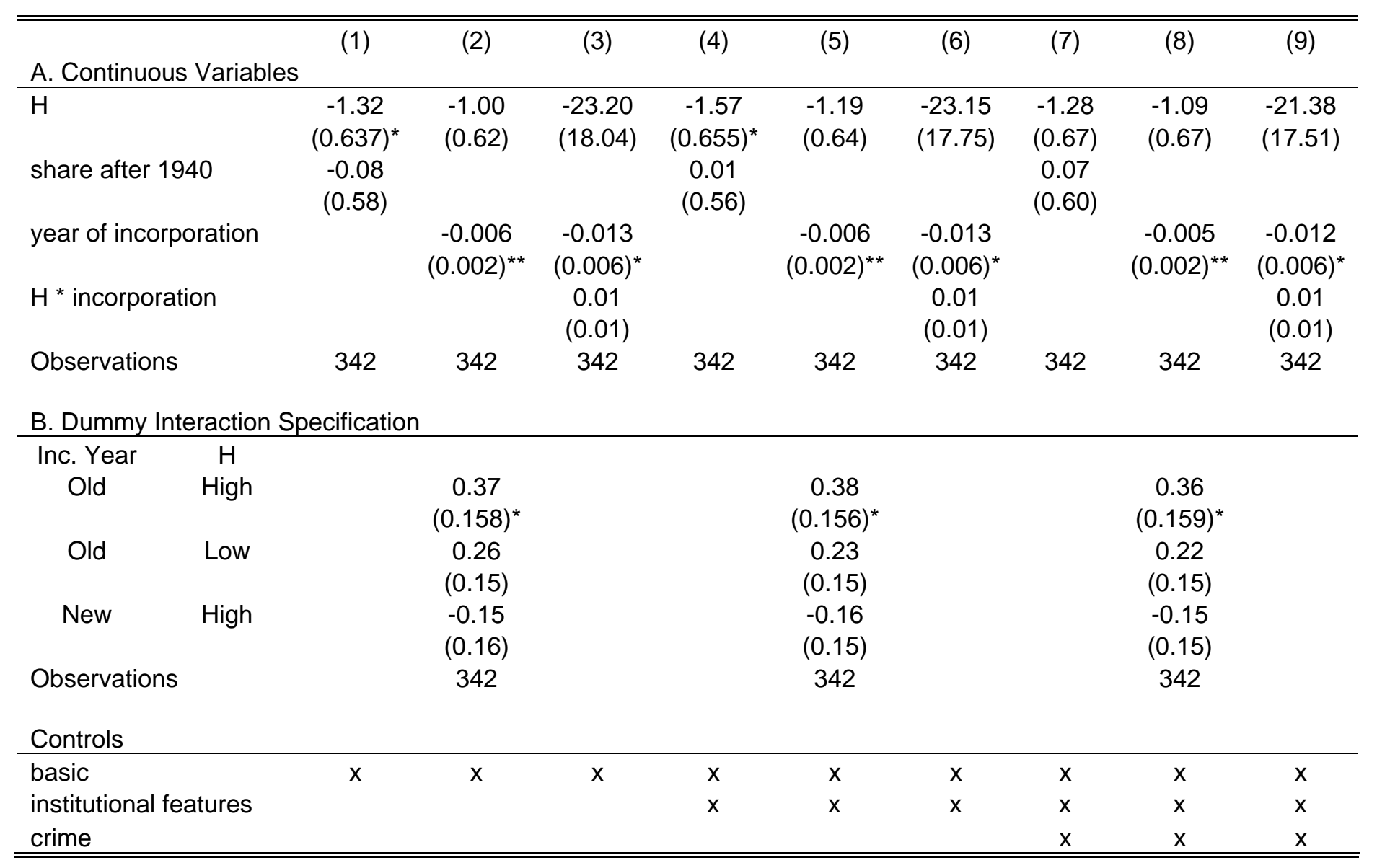

* Significant difference at the $0.05 \%$ level. ** Significant difference at the $0.01 \%$ level.

Notes: $H$ is the Hirfendahl index for poverty. This table reports BID adoption patterns in larger California cities, and shows that while heterogeneity is weakly associated with BID adoption, year of incorporation is strongly negatively associated with BID adoption. Basic covariates include population, population squared, racial shares, household characteristics, income measures, and business environment characteristics; a complete list is available in the appendix.

Source: Self-collected survey data on BID adoption; see appendix for complete source list. 
Table 4: The Impact of Heterogeneity of Poverty and Age on BID Adoption in Southern California

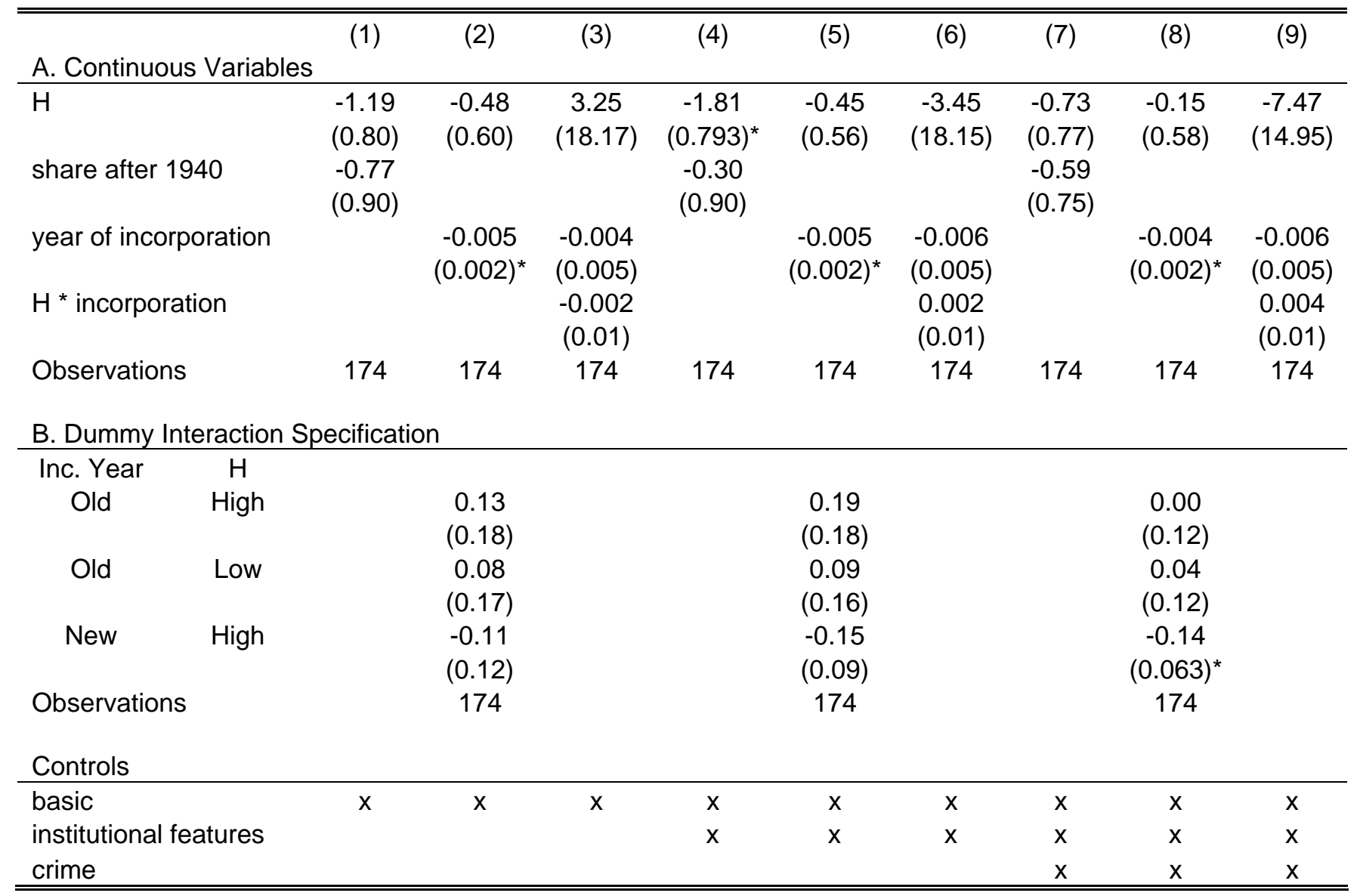

* Significant difference at the $0.05 \%$ level. ** Significant difference at the $0.01 \%$ level.

Notes: This table reports BID adoption patterns in the universe of Southern California cities, and shows that while heterogeneity is weakly associated with BID adoption, year of incorporation is strongly negatively associated with BID adoption. See Table 3 and Appendix for description of covariates.

Source: Self-collected survey data on BID adoption; see appendix for complete source list. 
Table 5: The Interaction of Heterogeneity and Age on BID Adoption

\begin{tabular}{|c|c|c|c|c|c|c|c|}
\hline & & (1) & (2) & (3) & (4) & (5) & (6) \\
\hline \multicolumn{8}{|l|}{ A. Larger Cities } \\
\hline \multirow[b]{2}{*}{$\begin{array}{c}\text { Incorporation } \\
\text { Year }\end{array}$} & \multirow[b]{2}{*}{ Heterogeneity } & \multicolumn{6}{|c|}{ Heterogeneity of } \\
\hline & & Poverty & Education & $\begin{array}{l}\text { Family } \\
\text { Income }\end{array}$ & Age & $\begin{array}{c}\text { Household } \\
\text { Type }\end{array}$ & Race \\
\hline \multirow[t]{2}{*}{ Old } & \multirow[t]{2}{*}{ High } & 0.36 & 0.38 & 0.34 & 0.41 & 0.54 & 0.16 \\
\hline & & $(0.159)^{\star}$ & $(0.22)$ & $(0.153)^{\star}$ & $(0.136)^{\star \star}$ & $(0.146)^{\star \star}$ & $(0.17)$ \\
\hline \multirow[t]{2}{*}{ Old } & \multirow[t]{2}{*}{ Low } & 0.22 & 0.53 & 0.35 & 0.25 & 0.55 & 0.30 \\
\hline & & $(0.15)$ & $(0.184)^{\star \star}$ & $(0.134)^{\star \star}$ & $(0.17)$ & $(0.166)^{\star \star}$ & $(0.17)$ \\
\hline \multirow[t]{2}{*}{ New } & \multirow[t]{2}{*}{ High } & -0.15 & 0.15 & 0.05 & 0.04 & 0.40 & -0.13 \\
\hline & & $(0.15)$ & $(0.22)$ & $(0.13)$ & $(0.16)$ & $(0.182)^{\star}$ & $(0.14)$ \\
\hline \multicolumn{2}{|l|}{ Observations } & 342 & 342 & 342 & 342 & 342 & 342 \\
\hline \multicolumn{8}{|c|}{ B. Southern California Cities } \\
\hline & & \multicolumn{6}{|c|}{ Heterogeneity of } \\
\hline Heterogeneity & $\begin{array}{c}\text { Incorporation } \\
\text { Year }\end{array}$ & Poverty & Education & $\begin{array}{l}\text { Family } \\
\text { Income }\end{array}$ & Age & $\begin{array}{c}\text { Household } \\
\text { Type }\end{array}$ & Race \\
\hline \multirow[t]{2}{*}{ Old } & High & 0.00 & $\mathrm{n} / \mathrm{a}$ & 0.32 & 0.16 & 0.44 & 0.98 \\
\hline & & $(0.12)$ & perfectly & $(0.30)$ & $(0.16)$ & $(0.199)^{\star}$ & $(0.160)^{\star *}$ \\
\hline \multirow[t]{2}{*}{ Old } & Low & 0.04 & predicted & 0.11 & 0.06 & 0.37 & 1.00 \\
\hline & & $(0.12)$ & & $(0.13)$ & $(0.15)$ & $(0.20)$ & $(0.001)^{\star \star}$ \\
\hline \multirow[t]{2}{*}{ New } & High & -0.14 & & 0.11 & -0.02 & 0.43 & 0.98 \\
\hline & & $(0.063)^{\star}$ & & $(0.22)$ & $(0.08)$ & $(0.24)$ & $(0.177)^{\star \star}$ \\
\hline Observations & & 174 & & 174 & 174 & 174 & 151 \\
\hline \multicolumn{8}{|l|}{ Controls } \\
\hline basic + institutio & + crime & $x$ & $x$ & $x$ & $x$ & $x$ & $x$ \\
\hline
\end{tabular}

* Significant difference at the $0.05 \%$ level. ** Significant difference at the $0.01 \%$ level.

Notes: By dividing age of incorporation into two dummies, one for above and one for below the mean, and doing the same for heterogeneity, this table tests whether the predicted high heterogeneity low year of incorporation combination best explains BID adoption. Among the larger cities sample, there is some evidence that this is the case. See Table 3 notes and appendix for description of covariates.

Source: Self-collected survey data on BID adoption; see appendix for complete source list. 
Table 6: Incorporation Year Most Important for Oldest Cities

\begin{tabular}{|c|c|c|c|c|c|c|c|c|c|c|}
\hline Incorporation Year & $\begin{array}{c}\text { (1) } \\
\text { share with } \\
\text { BIDs }\end{array}$ & (2) & (3) & (4) & (5) & (6) & (7) & (8) & (9) & (10) \\
\hline \multirow[t]{2}{*}{ less than 1890} & 0.52 & 0.58 & 0.55 & 0.54 & 0.59 & 0.58 & 0.55 & 0.58 & 0.56 & 0.54 \\
\hline & $(0.50)$ & $(0.152)^{\star \star}$ & $(0.163)^{\star \star}$ & $(0.162)^{\star \star}$ & $(0.144)^{\star \star}$ & $(0.151)^{\star \star}$ & $(0.154)^{\star \star}$ & $(0.148)^{\star \star}$ & $(0.156)^{\star \star}$ & $(0.158)^{\star \star}$ \\
\hline \multirow[t]{2}{*}{ between 1890 and 1910} & 0.25 & 0.42 & 0.41 & 0.40 & 0.41 & 0.40 & 0.39 & 0.40 & 0.39 & 0.38 \\
\hline & $(0.43)$ & $(0.183)^{\star}$ & $(0.190)^{\star}$ & $(0.185)^{\star}$ & $(0.175)^{\star}$ & $(0.181)^{\star}$ & $(0.179)^{\star}$ & $(0.177)^{\star}$ & $(0.182)^{\star}$ & $(0.181)^{\star}$ \\
\hline \multirow[t]{2}{*}{ between 1910 and 1950} & 0.20 & 0.38 & 0.37 & 0.38 & 0.35 & 0.35 & 0.35 & 0.34 & 0.34 & 0.34 \\
\hline & $(0.40)$ & $(0.190)^{\star}$ & $(0.20)$ & $(0.192)^{\star}$ & $(0.18)$ & $(0.19)$ & $(0.19)$ & $(0.19)$ & $(0.19)$ & $(0.19)$ \\
\hline Observations & & 342 & 342 & 342 & 342 & 342 & 342 & 342 & 342 & 342 \\
\hline \multicolumn{11}{|l|}{ Controls } \\
\hline \multicolumn{11}{|l|}{ Heterogeneity of } \\
\hline Poverty & & $x$ & $x$ & $x$ & & & & & & \\
\hline Education & & & & & $x$ & $x$ & $x$ & & & \\
\hline Family Income & & & & & & & & $x$ & $x$ & $x$ \\
\hline Basic & & $x$ & $x$ & $x$ & $x$ & $x$ & $x$ & $x$ & $x$ & $x$ \\
\hline Institutional Features & & & $x$ & $x$ & & $x$ & $x$ & & $x$ & $x$ \\
\hline Crime & & & & $x$ & & & $x$ & & & $x$ \\
\hline
\end{tabular}

* Significant difference at the $0.05 \%$ level. ** Significant difference at the $0.01 \%$ level.

Notes: This table, for the sample of larger cities only, shows that older cities are more likely to adopt BIDs.

Source: Self-collected survey data on BID adoption; see appendix for complete source list. 


\section{Appendix: Covariates}

Racial Shares

- share African American

- share Hispanic

- share Asian

- Source: Census of Population and Housing, 1980, 1990 and 2000, accessed from UCLA and ICPSR

Household Characteristics

- mean household size

- share of households with children

- share of single mother-headed households

- population share 65 or older

- share with high school education

- share with bachelor's degree

- Source: Census of Population and Housing, 1980, 1990 and 2000, accessed from UCLA and ICPSR

Income

- median household income

- mean family income

- Source: Census of Population and Housing, 1980, 1990 and 2000, accessed from UCLA and ICPSR

Business Characteristics

- retail sales per capita

- total sales per capita

- city government expenditure per capita

- Source: City and County Data Books, 1988, 1994 and 2000, accessed via the University of Virginia; contain information from the 1982, 1987 and 1997 economic censuses 
Crime

- offenses per capita

- clearance rate

- Source: FBI Uniform Crime Reports, 1980, 1990, 2000, accessed via ICPSR

Institutional Characteristics

- year of incorporation

- whether council has at large members

- whether city operates under homerule

- whether or not city uses mayor-council form of government

- Source: 1987 Census of Governments, accessed from Census 